\title{
The Satisfaction of Patients with the Management of Kidney Stones in Malaysia: A Qualitative Study
}

\author{
Ahmed Ibrahim Nouri ${ }^{1, *}$, Mohamed Azmi Hassali², Azhar Amir Hamzah ${ }^{3}$ \\ 'Washington University of Health and Science, Ramallah, PALESTINE. \\ 2Discipline of Social and Administrative Pharmacy, Universiti Sains Malaysia, Penang, MALAYSIA. \\ 3Department of Surgery, Hospital Universiti Sains Malaysia, Kelantan, MALAYSIA.
}

\begin{abstract}
Background: Kidney stones form by the precipitation or crystallization of minerals and urinary constituents. It is a common problem worldwide manifested with recurrent intermittent pain episodes, surgical interventions, and medication consumption which affect the patients' quality of life. The current study explored patients' satisfaction with the management of kidney stones disease, along with their experience with the treatment. Methods: Qualitative face-to-face semi-structured interviews were conducted with kidney stones patients from Hospital Universiti Sains Malaysia in January 2018. Interviews were verbatim transcribed and thematic content analysis was carried out to understand the phenomena of patients' experiences. Results: The fifteen patients who were interviewed judged their health and clinical outcomes based on several aspects. They build perceptions and make opinions based on outcomes including whether the disease is cured or not, relief of symptoms, prevention of disease progression, or absence of symptoms relapse, and whether the diagnostic and follow-up tests became normal. Based on the interviews, most
\end{abstract}

patients were more satisfied with medical treatment than interventional treatment. Conclusion: The satisfaction towards the management of kidney stones was influenced by the treatment option chosen for each patient, expectations and perceptions of the treatment and disease, and healthcare system-related issues. This understanding could improve targeted support and therapy provided by health care providers so patients can better deal with the many disputes they face during suffering from kidney stones. Key words: Satisfaction, Perception, Kidney stones, Interview, Qualitative research.

\section{Correspondence}

Dr. Ahmed Ibrahim Nouri, RPh., PharmD., MSc. (Clinical Pharmacy)

Washington University of Health and Science, 9993900 Ramallah, PALESTINE.

Email id: ahmad090@hotmail.com

DOI: 10.5530/jyp.2021.13.60

\section{INTRODUCTION}

The prevalence of patients with kidney stones disease was $1.8 \%$ among patients admitted to a teaching hospital in Malaysia. ${ }^{1}$ With advancing medical and surgical management of kidney stones disease, there is a variety of approaches to treat patients. ${ }^{2,3}$ Options for treatments depending on the treating physician, the disease state, and patient preferences. Medical treatment is mostly used for the prevention of kidney stones, however, with the availability of non-invasive options patients are becoming less careful about preventing the disease. ${ }^{4}$ Patients' preferences are mediated by various factors such as duration of suffering from disease, disease severity, the duration between painful episodes, invasiveness of procedures, duration and onset of recovery of treatment, and others. ${ }^{3,5}$ To understand patients' preferences, a study used decision modeling to comprehend the decision-making and choices of the treatment of kidney stones disease. ${ }^{6}$ The patients favored less-invasive procedures and shortterm treatments. Hence, medical treatment was less favored than Extracorporeal Shockwave Lithotripsy (ESWL) because of its short onset of treatment. Also, medical treatment was favored over invasive procedures. ${ }^{7}$ Psychological illnesses such as anxiety or depression are strongly related to diseases that cause recurrent painful crises. ${ }^{8}$ A study investigated the association between recurrent renal colic and symptoms of anxiety and depression. It demonstrated that more than half of renal stones patients with recurrent painful episodes found to have depression $(59 \%, p=0.009){ }^{9}$ A case-control study evaluated the association between recurrent pain episodes of renal colic caused by kidney stones and stressful life events where stressful life events were reported by measuring the Social
Readjustment Rating scale. The study demonstrated an association between stressful life events and recurrent renal colic. ${ }^{10}$ Hence, exploring patient's satisfaction towards renal stone disease management and providing the medical literature with an analysis of patient's perceptions of the disease and its management considered useful to achieve optimum health care.

\section{METHODLOGY}

The study was conducted in Hospital Universiti Sains Malaysia (HUSM), Kelantan, Malaysia. The study followed a qualitative approach, a phenomenological study by interviewing patients. Figure 1 presents the flowchart of the study. Phenomena may be events, situations, experiences, or concepts. Everything is phenomenon. Hence, the phenomenological study design investigates in-depth descriptions and does a close analysis of how patients express meanings of their experiences from the first-person point of view. Thus, exploring patients' feelings toward treating kidney stones by surgery or drugs, comprehension of meanings of terms related to kidney stones like ESWL and catheterization, discovering patients' perceptions of the reasons that caused their kidney stones, and their beliefs about the use of herbal products and else all fall under the umbrella of the phenomenological approach. ${ }^{11-15}$

The interviewers were the principal investigator of the study (male, Pharm.D, MSc. Clinical Pharmacy candidate) accompanied by a local Malaysian (female, MD, research assistant) as a facilitator. 


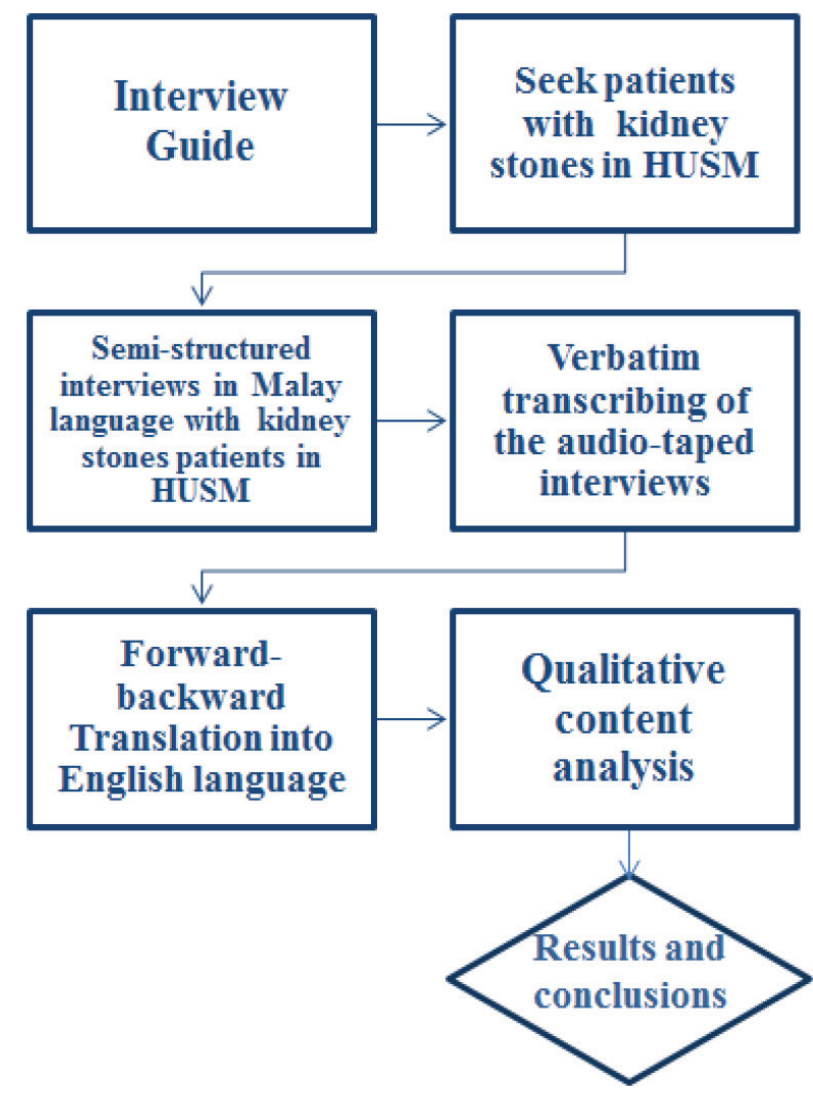

Figure 1: Flowchart of the study.

The recruitment and interviewing process started on 9th September 2017 and ended on 20th October 2017. The patients for this research were all patients receiving medical consultation and treatment from HUSM, either as an out-patient from the Urology Clinic or as an in-patient from Surgical Wards or as out-patient from the ESWL room. Patients were recruited purposively based on the differences in their management strategy, namely, self-stone expulsion with the aid of medications, extracorporeal shockwave lithotripsy (ESWL), percutaneous nephrolithotomy (PCNL), ureteroscopy (URS), or else. ${ }^{16}$ In HUSM, the urology clinic has two days of sessions per week from 8:30 a.m. to 2:00 p.m. All patients have prescheduled appointments. A list of all patients' appointments was retrieved beforehand through the (Lifeline) which is a database of all HUSM patients. It is then printed out, to single outpatients with kidney stones, the registration number of each patient was keyed in individually into the system to access the information on their diagnosis, contact number, and address. Patients coming for a follow-up visit, their consecutive diagnosis was mentioned, which was the way to point them out. A total of 140 patients were called, some patients did not pick up, some were far to be reached, others refused to be interviewed. Only 31 answered the call, 2 patients refused to be interviewed due to disinterest and old age. While 15 were interested and fulfilled the selection criteria. The attempts to call patients were repeated several times, if they do not respond after the fourth call within two days, they were ruled out. Patients who agreed to be interviewed had the choice to select the proper time and place to interview them; some chose to be interviewed in their house, others chose to be interviewed in the hospital. Several of the patients are interviewed out of the hospital areas. It is important to note that seeking patients kept until the saturation point attained. In which, there was no more information revealed from the interviews, and the patients were repeating most of the information. This was confirmed upon analyzing the last three interviews with patients.

The interviewers used an iPhone as a recording device and the interview protocol as a guide for the interview, what to do or say next after a patient has answered a question. The interview guide was made based on reading and digesting several articles related to the kidney stones disease..$^{9,17-26}$ The interview guide was validated to ascertain that the interview questions have been appropriately designed to answer the study objective adequately. Validation was done using face validity and pilot study. The pilot study was conducted with two patients, one from the ESWL room and the other one was from the outpatient urology clinic in HUSM. A preliminary content analysis was done to assess the quality of the gained information. The patients gave their feedback on the interview by asking them about the duration, the understandability of questions, and redundancy. Editing was done accordingly based on their comments. The duration of the interviews was assessed, $19 \mathrm{~min}$ and $23 \mathrm{~min}$; this suggests that the interview's duration was up to expectations as it was estimated to be between 20 and 25 min per interview. Hence, based on the pilot study, the interview guide considered as an interview protocol serves the aspects of the research objectives.

This study included patients who are willing to speak and share information with a confirmed diagnosis of kidney stones disease and are treated with HUSM. Patients under the age of 18 years, pregnant patients, and patients who have an end-stage renal disease were excluded.

Patients were called and approached at the clinic, some patients did not pick up, some were far to be reached, others refused to be interviewed. The attempts to call patients were repeated several times, if they do not respond after the fourth call within one week, they were ruled out. Of the patients who answered the call, 2 patients refused to be interviewed due to disinterest.

QDA is composed of processes and procedures that transform the collected qualitative data into the structure of understanding or interpretation of the people and situations that are being investigated. In other words, QDA is a collection of interpretation processes, where the researcher engages with the data, working with data, cleaning it, organizing it, looking for patterns, discovering what is essential and what is to be learned, and decide what is relevant, what can categorize and what can be connected.

After verbatim transcription of all recordings and numbering of each line in the transcript, the transcriber listens to the record while following with the written transcript as a double-checking process to correct any errors or missed parts. To ensure the anonymity of participants, interviewees got tags of (patient $\# 1, \# 2, \# 3$, etc.), where their consecutive transcripts will not include any personal identification said during the interview.

Thematic content analysis undertaken to transcripts generated themes that reflect the descriptions of participants' experience, analyzing the interview data and identify similarities and patterns, coding then done to the transcripts line by line by the authors.

\section{RESULTS}

A total of 15 patients were interviewed, they were interviewed in various places according to their preferences, some were interviewed at the hospital while others were interviewed at their homes. The patients were 8 males (53.3\%) and 7 females (46.7\%) with an age range of 24 to 79 years old $(57.3 \pm 13.6$, Mean $\pm S D)$. Patients' socio-demographic and disease history are shown in Table 1.

The interviews were conducted in the presence of the researcher, facilitator, and the patient. Six out of the fifteen patients were accompanied by family members; however, they did not interfere in the interview. Except 
Table 1: Socio-demographic and disease history information of interviewed patients.

\begin{tabular}{|c|c|c|c|c|c|c|c|c|c|c|c|c|}
\hline 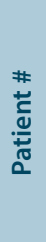 & 导 & 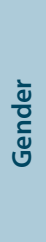 & 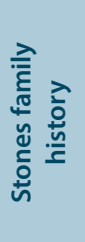 & 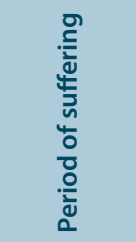 & 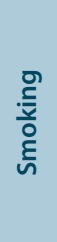 & 号 & 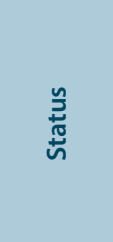 & $\begin{array}{l}\overline{0} \\
\frac{0}{0} \\
\frac{\varrho}{\alpha}\end{array}$ & 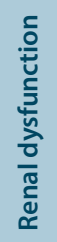 & $\begin{array}{l}\tilde{y} \\
\stackrel{0}{0} \\
\stackrel{0}{\sigma} \\
\stackrel{\sigma}{0}\end{array}$ & 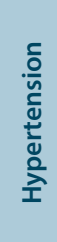 & $\begin{array}{l}\frac{\pi}{\frac{\pi}{c}} \\
\frac{0}{0} \\
\frac{0}{\frac{0}{n}} \\
\frac{1}{0}\end{array}$ \\
\hline 1 & 71 & $\mathrm{~F}$ & Yes & 4 years & Yes & Unemployed & Married & No & No & Yes & No & Yes \\
\hline 2 & 39 & $\mathrm{~F}$ & No & 7 years & Yes & Unemployed & Married & No & No & No & Yes & Yes \\
\hline 3 & 57 & M & No & 3 months & yes & Employed & Married & No & No & Yes & No & Yes \\
\hline 4 & 65 & M & No & 2 years & yes & Unemployed & Married & No & No & No & Yes & No \\
\hline 5 & 49 & $\mathrm{~F}$ & Yes & 10 years & Yes & Employed & Married & No & No & Yes & No & No \\
\hline 6 & 59 & $\mathrm{~F}$ & Yes & 11 months & Yes & Retired & Married & No & No & Yes & Yes & Yes \\
\hline 7 & 55 & M & No & 4 years & No & Employed & Married & No & No & No & No & Yes \\
\hline 8 & 55 & $\mathrm{~F}$ & No & 6 months & Yes & Employed & Married & No & No & No & Yes & Yes \\
\hline 9 & 66 & $\mathrm{~F}$ & No & 2 years & Yes & Unemployed & Married & No & No & Yes & Yes & Yes \\
\hline 10 & 47 & M & No & 18 months & Yes & Employed & Married & No & No & No & Yes & Yes \\
\hline 11 & 60 & $\mathrm{~F}$ & No & 3 years & Yes & Unemployed & Married & No & No & No & No & Yes \\
\hline 12 & 24 & M & No & 2 months & No & Employed & Married & No & No & No & Yes & No \\
\hline 13 & 67 & M & No & 2 years & No & Retired & Married & No & No & No & No & Yes \\
\hline 14 & 66 & M & No & 4 years & No & Employed & Married & Yes & No & No & Yes & Yes \\
\hline 15 & 79 & M & Yes & 25 years & Yes & Employed & Married & No & No & No & Yes & Yes \\
\hline
\end{tabular}

Table 2: Types of treatment of kidney stones.

\begin{tabular}{|c|c|c|c|c|c|c|c|c|c|c|c|c|c|c|c|c|}
\hline Patient & 1 & 2 & 3 & 4 & 5 & 6 & 7 & 8 & 9 & 10 & 11 & 12 & 13 & 14 & 15 & Total \\
\hline Gender & $\mathrm{F}$ & $\mathrm{F}$ & $\mathrm{M}$ & $\mathrm{M}$ & $\mathrm{F}$ & $\mathrm{F}$ & $\mathrm{M}$ & $\mathrm{F}$ & $\mathrm{F}$ & $\mathrm{M}$ & $\mathrm{F}$ & $\mathrm{M}$ & $\mathrm{M}$ & $\mathrm{M}$ & $\mathrm{M}$ & \\
\hline Age & 71 & 39 & 57 & 65 & 49 & 59 & 55 & 55 & 66 & 47 & 60 & 24 & 67 & 66 & 79 & \\
\hline ESWL $^{*}$ & $\mathrm{x}$ & $\mathrm{x}$ & $\mathrm{x}$ & $\mathrm{x}$ & $\mathrm{x}$ & $\mathrm{x}$ & & $\mathrm{x}$ & & & & & $\mathrm{x}$ & & & 8 \\
\hline $\mathrm{PCNL}^{*}$ & & & & & $\mathrm{x}$ & $\mathrm{x}$ & & $\mathrm{x}$ & & & & & $\mathrm{x}$ & $\mathrm{x}$ & & 5 \\
\hline URS $^{*}$ & $\mathrm{x}$ & $\mathrm{x}$ & & $\mathrm{x}$ & & & $\mathrm{x}$ & & & & $\mathrm{x}$ & $\mathrm{x}$ & $\mathrm{x}$ & & $\mathrm{x}$ & 8 \\
\hline Stent & & $\mathrm{x}$ & & & & $\mathrm{x}$ & & $\mathrm{x}$ & & & $\mathrm{x}$ & $\mathrm{x}$ & $\mathrm{x}$ & $\mathrm{x}$ & $\mathrm{x}$ & 8 \\
\hline Self-expulsion & & & & & & & & & $\mathrm{x}$ & $\mathrm{x}$ & & & & & & 2 \\
\hline
\end{tabular}

*ESWL: extracoproeal shockwave lithotripsy, PCNL: percutaneous nephrolithotomy, URS: ureteroscopy

for one patient who was unable to continue his interview, his wife continued the interview on his behalf. The duration of the interviews ranged from 18 to $49 \mathrm{~min}(25 \pm 3 \mathrm{~min}, \mathrm{Mean} \pm S D)$. Table 2 shows the types of treatment that each patient received.

Transcripts of the audio-recorded interviews were subjected to qualitative content analysis which involved coding and classifying data, coding was undertaken by the authors to identify relevant words from the transcripts to extract data that is informative and to uncover valuable information hidden in each interview. ${ }^{27,28}$ Hence, interviews were reported thematically. The thematic content analysis of the data revealed a total of four themes, namely, Treatment of kidney stones disease, Satisfaction towards treatment, perceptions toward the treatment, and treatment barriers with several subthemes as shown in Table 3.

The fifteen patients who were interviewed judged their health and clinical outcomes based on several aspects. They build perceptions and make opinions based on outcomes including whether the disease is cured or not, relief of symptoms, prevention of disease progression, or absence of symptoms relapse, and whether the diagnostic and follow-up tests became normal. Based on the interviews, most patients were more satisfied with medical treatment than interventional treatment.

\section{Ability to Choose Treatment}

Patients mentioned their thoughts about the choice of therapy, whether they had the option to choose, and why do they think that treatment was chosen for them.

"I was given a choice to do laser and put stent" (P06) [patient was referring to ESWL]

Some patients preferred pharmacological therapy and ask the doctor to go for it despite the doctor's suggestion to go with procedures.

"I said let us try to take medicine first, doctor" (P09) 
Table 3: Themes and sub-theme emerged from the qualitative data analysis.

\begin{tabular}{|c|c|}
\hline Themes & Subthemes \\
\hline $\begin{array}{l}\text { Treatment of } \\
\text { kidney stones } \\
\text { disease }\end{array}$ & $\begin{array}{l}\text { - } \quad \text { Ability to choose treatment. } \\
\text { - } \quad \text { The frequency of undergoing kidney stone treatment. } \\
\text { - } \quad \text { Effectiveness of procedures } \\
\text { - } \quad \text { Pharmacological Treatment } \\
\text { - } \quad \text { Complementary and alternative medicine } \\
\text { - } \quad \text { Side effects of medications }\end{array}$ \\
\hline $\begin{array}{l}\text { Satisfaction } \\
\text { towards } \\
\text { treatment }\end{array}$ & $\begin{array}{l}\text { - Satisfaction towards the treatment of kidney stones } \\
\text { - } \quad \text { Satisfaction towards the pain management } \\
\text { - } \quad \text { Preference of treatment } \\
\text { - } \quad \text { Condition after treatment }\end{array}$ \\
\hline $\begin{array}{l}\text { Perceptions } \\
\text { toward the } \\
\text { treatment }\end{array}$ & $\begin{array}{l}\text { - Opinions about treatment } \\
\text { - } \quad \text { Patient's background about the disease } \\
\text { - The condition of the kidney stone }\end{array}$ \\
\hline $\begin{array}{c}\text { Treatment } \\
\text { barriers }\end{array}$ & $\begin{array}{l}\text { - } \quad \text { Healthcare team behavior } \\
\text { - } \quad \text { Family members reaction } \\
\text { - } \quad \text { Effect of disease on daily life } \\
\text { - } \quad \text { Scared of recurrence }\end{array}$ \\
\hline
\end{tabular}

\section{The Frequency of Undergoing Kidney Stone Treatment}

The frequency of treatment varies according to the treatment method; however, most patients did mention that they got treated many times for kidney stones.

Some patients underwent many times of shooting treatments, and they are still having kidney stones disease.

"Many times." (P08)

"After that, I was shot two to three times." (P13)

Also, the period the stent is being inserted into the patient's body was a concern to many patients.

"I was asking how many months this stent will be used. He said only 3 months." (P13)

"I used stent for four years, changed it 4 times ... if I'm not mistaken! ... 3 months once." (P15)

\section{Pharmacological Treatment}

There are many different types of medications that were consumed by the patients, such as painkillers, medical expulsive therapy, and alkali drugs, in addition to the medications used for other medical conditions.

Most of the patients agreed that the drugs are effective in pain management. "After taking the medicine, the pain was gone immediately" (P09)

"Medicine was given by the clinic, the pain stopped." (P08)

"The medicine given for kidney helped a lot." (P03)

"My waist felt comfort after taking that medicine. I can stretch, and it reduced my pain, I can perform my Salah (prayer)" (P01)

On the contrary, many patients did not benefit from the drugs. One patient claimed that the Tramadol does not affect relieving pain, as the pain is still there after taking it.

"When I am in so much pain, I take Tramal, but the medicine is not effective." (P08)

To a patient taking potassium citrate is not effective to reduce pain, although it is not a drug to reduce pain. But he does experience that his urination is going smoother.

"There is no effect of pain-relieving, but I feel more comfortable to urinate." (P07) [Talking while holding potassium citrate bottle]
Some patients did not know the name of their medicines and were describing it generally.

"I am taking a white-colored medicine and I take it in the morning and evening” (P04)

\section{Complementary and Alternative Medicine}

Many patients used Complementary and alternative medicine (CAM) to aid the treatment of their kidney stones, some of them view it as effective while others do not believe in it.

"I tried so many treatments other than the hospital's way [sic]" (P15)

"Massaging is also useless towards the pain." (P14)

Patients do not take CAM because they do not believe in its effectiveness or are worried about its consequences.

"I don't dare because I am afraid that there might be side effects" (P07)

"I know that village medicine, a leaf of turtle egg, the one my friend suggested to me. But I don't take it." (P07)

\section{Effectiveness of Procedures}

With the variety of options, many patients had to experience more than one mode of treatment as one of the treatments may not be effective.

Some patients underwent "shooting" treatment to break the kidney stones into smaller pieces as dust, their opinions about this treatment are positive, they think that this treatment is effective to treat kidney stones. Patients with a positive opinion toward the treatment were based on that pain was decreased enormously after treatment.

"The pain was gone. But some of the kidney stones still exist." (P07)

"The pain getting reduced and disappeared." (P07)

On the contrary, many patients suffered from a lot of pain because of the stents.

"It was hurt when the stent was placed. When I sit in the car [patient demonstrate to show her pain] I could not hold it" (P06)

"The stent is an experience which is the most [Patient emphasizes this word by seconds and support her forehead] horrible... most painful!!" (P08)

There was one patient who thinks the "shooting" treatment is not so effective because he is requested to carry out a second ESWL. The doctor told him there are still some kidney stones remaining inside his body.

"After some time from the first operation, they got to know that there are a few stones which haven't clear out. So, I did second shooting [the patient is speaking in unsatisfied tone]" (P05)

\section{Satisfaction Towards the Treatment of Kidney Stones}

Satisfaction of patients was at most towards ESWL treatment. (Outcomes of the treatment were very effective)

"Yes, I am very satisfied, after I did the shooting, I felt that my urination was going smoother, and I experienced less pain." (P02)

Patient unsatisfied with the period of recovery after EWSL the patient wishes the effect of the treatment to be faster.

"After that, ESWL fired a splinter on the kidney wall until a month of the abscess. That's why I'm less satisfied. Many years to recover." (P13)

Four patients were treated with stent insertion, most of them used unsatisfied tone and expressions.

"I'm not satisfied too. It was because this treatment took a long time... and because of the mistake, it was the wrong stent. Even the doctor, had taken the wrong stent. This has truly happened. The evidence exists." (P13)

And others simply complained about it either because of pain or it makes them feel uncomfortable. 
"Ah, not satisfied. In coming October, the doctor will remove the stent." (Patient uses unsatisfied tone.) (P08)

"I do not like it very much when it comes to the wire because of the prolonged pain”. (P14)

"I am not willing to put in the stent... I can feel the wire is inside my body. It is quite uncomfortable..." (P15)

\section{Satisfaction Towards the Pain Management}

Upon asking patients about the use of medications to treat their painful episodes

"Yes, the pain became less with that medicine. I could get up and move and it was less painful" (P01)

"Hmm ... After I consumed the drug, I felt that the difficulty in urination had been decreased and I felt very less pain" (P02)

While when asking a patient about painkillers efficacy

"Slightly effective only. Pain not hundred percent vanished" And elaborated with. "My pain has gone hundred percent immediately after the operation [patient was referring to PCNL as operation]" (P05)

Many patients were not satisfied with the use of drugs to reduce their pain, the kidney stones pain was so overwhelming.

"I felt less pain. The next morning, I felt pain again. I was still in pain on the third day, and my son told me not to take Celebrex and try to take an injection at the hospital. I could not handle the pain anymore" (P06)

A patient chooses to self-expel the kidney stone and described the experience of expelling the stone and the pain that has been encountered, [the patient was talking in a very satisfied tone and proud]

"When the stone came out, I felt pain. But not very painful. Felt a little in pain. It was something want to come out. I can feel there was something want to come out. So, I caught it. There were really small particles. Before it, I did not know whether there were particles. The particles are like a rice grain" (P09)

While the other patient described it as "a hell of a pain"

\section{Preference of Treatment}

Patients were asked about their preferences about the treatment, and whether they choose the same treatment again.

Almost all patients stated that their doctor provided options for treatment that is consistent with their specific case, however, they shared the answer that if they had to choose again, they would prefer the use of medicines.

Some patients prefer having medicine instead of doing treatments that involve an operation.

"I said let us try to take medicine first, doctor" (P09)

"For me, it is best if taking the medicine can destroy the kidney stones and the kidney stones come out, it's much better." (P02)

\section{Condition After Treatment}

After treatment, patients expected to feel free of pain and ready to live a normal life, most of them were talking in a tone that the condition after treatment was not up to expectations.

Many patients claim that they experienced extreme pain after the treatment of kidney stones.

There is one patient who states the pain after stent insertion was very horrible and unbearable. They experience pain at any time while they are doing normal activities like driving a car.

"The pain is like when you are getting a bite from ant" (P15)

"... but after the surgery, I can feel the pain near the cut area." (P14)
Some patients are still having kidney stones inside their bodies even after the treatment. And this was a shocker to the patients to doubt the efficacy of the treatment.

"But unfortunately, after the treatment, the kidney stone was not broken into pieces." (P03)

"After the laser, the stone is still there." (P11)

Blood in the urine was one of the main concerns by patients after treatment.

"Yes, I walk in pain just like the woman who gave birth" (P06)

\section{Perception Towards Treatment}

Most of the patients believed that they would recover from the disease.

"This current pain of the stone is just temporary, and it would not last for whole life." (P2)

"Yes, I do feel scared, but I have confidence and I admitted myself to believe that is the best treatment for me." (P02)

While there are patients who do not believe in the effect of medications "I usually... This medicine...I'm the type... [Patient as if he hesitated to answer]... I eat medicines, but I don't like medicines" (P12)

Some patients do not believe in traditional medications; most of the patients have confidence in modern drugs.

"I have received many offers from my friends to try traditional treatment, but I do not believe it completely." (P08)

"I believe in treatments and hospital medications." (P05)

Medications do help in controlling the pain, but the pain will strike again when the effect of the drugs is gone, that is the reason to keep adherent and not to stop the drug.

"Usually when the medicine effect is gone, I will feel the pain again." (P07) Some of the patients feel that the treatment is not truly effective because of kidney stones because even after the treatment was done there were stones remained. Patients chose to deal with the pain either by tolerating it or taking non-prescribed medications like painkillers.

Most patients did not seek medical attention despite having renal colic and feeling of pain.

"First time when I felt the pain, I did not consult a doctor immediately. I tolerated the pain for 2 weeks" (P02)

"As long as I can bear with the pain, I will not take the painkiller. Because I know it is not healthy to take lots of painkillers" (P03)

Seek medical attention when experienced symptoms other than pain such as bloody urine or unable to urinate.

"The worst situation was when I could not urinate. When this happened, I went to HUSM" (P15)

"I only made up my mind to consult a doctor when there is blood in my urine. Besides, I also experienced difficulty in urination in the 2 weeks, but I bore with it until I saw the blood in my urine." (P02)

"I went to the clinic when there was blood in my urine" (P03)

\section{The Condition of the Kidney Stone}

When patients went to hospital or clinic for treatment, doctors informed them about the conditions of their kidney stones inside the body.

"I didn't notice the size since it is too small" (P07)

"It is $0.6 \mathrm{~cm}$ " (P12)

"The right side is $1.6 \mathrm{~cm} . "$ ( $\mathrm{P} 08)$

"The kidney stones are on my right side" (P01)

Some patients were aware of the wires used, sizes, and purpose of using them.

"The size of the wire is just like (patient shows the pinky finger) ... to make the track wider... so that the rest of the stone can be passed smoothly" (P14) 
One patient is having staghorn kidney stones that are more difficult to remove.

"But now, he said that the stones on the left were a little bit difficult because it was linking. Like a deer horn." (P13)

\section{Patient's Background About the Disease}

The patients had a different educational level but did not affect their disease background.

"I did not know that bloody urine came from the kidney stone" (P06) [tertiary education]

"But I do not think that high blood pressure causes a kidney stone." (P14) [No formal education]

\section{Healthcare Team Behavior}

Good communication skills and cooperation with the patients. The doctor's friendliness was the main contributor that leads to satisfaction of the patient towards the treatment.

Some patients felt comfortable and provided good comments about the doctors.

"Regarding the doctor, there is no problem because this doctor is friendly." (P08)

Many patients mentioned their frustration about health care providers either nurses, staff, or even physicians.

"The doctor asked me "what have you did so you can walk easily like this." I replied, "I took 'Daun kadok'. And the doctor scolded me (you cannot drink something like that!!)” (P06)

One of the patients suggested a solution for their behavior that makes patients feel scared or in doubt.

"Do not prepare all the tools in front of the patients. Then, do not talk about the other doctors in front of us. For example, he said that doctor gave the big size of the stent. So, there is no need to speak about doctor's mistakes with the patients. Ok!! ... I am always open; every human does mistakes," (P06)

Lack of equipment of hospital, hospital out of stock of some drugs, hospital limiting the medicines given to patients was very let downs to patients and source of dissatisfaction.

\section{Effect of the Disease on Daily Life}

Some patients claim that the degree of pain of kidney stones is very high. For example, they even cannot do daily chores.

"I already felt the pain for a long time. I am in pain for years." (P09)

"I felt pain when I do house chores, and I perform salah (prayer) in pain." (P01)

Patients claim that they can feel the stone in the urinary tract and facing difficulty in defecation and urination.

"... When the small chunk of the stone went into the urinary tract and was going to get out, I can feel the pain" (P14)

"The worst situation was when I could not urinate" (P15)

"I had difficulty in urination and defecation. It is very painful." (P15)

Many patients were worried about their daily life such as interrupted sleep because of pain, disease interference with their daily life like losing time to be spent with their family or work because of hospitalization or clinic visits.

\section{Scared of Recurrence}

Some patients feel encouraged to adhere to drugs and take treatment because they are worried about stone recurrence.
"I only feel worried, in this week. I feel pain again just like the pain from a kidney stone. I am scared it is kidney stone again. It feels so painful. I have never felt so pain before" (P09)

"In my opinion, I have not yet got well because there are still leftover kidney stones ... but the situation now far better than before because I am just worried about one thing only, about kidney failure." (P05)

\section{DISCUSSION}

The findings of this study were based on the analysis and results through the semi-structured interviews of 15 patients who are or who had been suffering from kidney stones disease.

Patients judge their health and clinical outcomes based on many aspects and build perceptions and make opinions based on these outcomes. These outcomes include whether the disease is cured or not, are the symptoms are relieved, the disease is prevented, or disease symptoms will not recur, and whether the diagnostic and follow-up tests normalized. This study reports the satisfaction of patients toward treatment of kidney stones disease in a teaching hospital in Malaysia and is mainly based on the perceptions of patients without regard to clinical solidity. It relates to three aspects, namely, satisfaction toward pain management, satisfaction toward kidney stones treatment, and perceptions of the disease.

The patients mostly knew about their current condition, however, a big part of the interviews was discussing the pain that the patients experience, whether before seeking medical attention, during treatment, or after treatment. The pain is the cornerstone that shifts the scale of patient satisfaction toward healthcare. ${ }^{29}$ After treatment, patients are expected to feel free of pain and ready to live a normal life. However, most of them were talking in a tone that the condition after treatment was not up to expectations.

Treatment of kidney stones varies from patient to patient; hence, aspects of treatment and its type had a big influence on the direction of the interviews, the way the patients expressed their feelings, also, the way they describe the treatment. For example, Extracorporeal shockwave lithotripsy is a very complex term, all patients treated with it used the term (shot, shooting treatment, shoot, ...), even the physicians themselves used this verb (shooting) to tell the patient about the treatment like P04 was wondering about the term and expressed their wonder during the interview "I asked him how you will shoot me?! [Patient saying with wonder]". However, many patients preferred having medicine instead of doing treatments that involve an operation. In the study by Kuo et al., patients ranked ESWL as their favored option which came above medical therapy then invasive procedures, this was attributed to that medical therapy is a long-term treatment, and patients prefer to be treated soon. ${ }^{6}$ These reports coincide with the findings of the current research where most patients favored medical treatment over invasive procedures. Upon asking the patients if they may choose again how to be treated, most of them agree with not choosing invasive procedures again.

Mostly, patients tend to take traditional medicines because of the lack of confidence in hospital medicines. However, most of the interviewed patients did not state that they do not trust the hospital's drugs. Conversely, they thought that the use of both traditional medicines and medicine prescribed by the hospital may lead to some severe consequences.

Mostly, the patients were satisfied with all aspects of the disease and its management. However, they had certain concerns and comments regarding the pain, the type of therapy, and their expectations as well.

Some patients expected that kidney stones can be treated with drugs as they do not want to suffer from post-operative pain. While other patients felt that the treatment is not truly effective because of kidney stones because stones remained. Besides, some patients suffering from severe pain 
after the treatment, which made them believe even more the treatment was not effective. Healthcare professionals had to reassure the patient and explain to the patient about the expected results of the treatment and act properly with any patient discomfort after the treatment. Furthermore, they must explain the remained stones and provide preventive measures and proper pain control to allow the patient to live normally and be satisfied as most of the patients had concerns about a recurrence of the disease.

Most of the interviewed patients were educated and know the medicine and scientific terms of the treatment for kidney stones. In general, the more educated the patient more satisfaction can be attained. Educating the patient about his disease may modulate their expectations about the treatment.

A limited sample was recruited to conduct qualitative interviews which is usually very acceptable in qualitative research if the saturation point is attained, where no new information can be obtained from the adding of subjects. Recall bias may present as all the information is collected from the patients through the interview. The information given by the patients was unable to be verified, thus there is a higher chance for misinformation, which will greatly influence the outcome of the study. Moreover, the nonverbal aspects of the interviews were not taken into consideration.

\section{CONCLUSION}

The satisfaction towards the management of kidney stones was influenced by the treatment option chosen for each patient, expectations and perceptions of the treatment and disease, and healthcare system-related issues. The study did not aim to quantify how much they are satisfied but to learn about their experience that affect the satisfaction. With the limited medical literature about what kidney stones patients' feelings and experiences, this qualitative study provided real evidence about patients' opinions and perceptions toward their treatment. The understanding of patients' experience will improve therapy by health care providers so patients can better deal with the many disputes they face during suffering from kidney stones.

\section{Ethical Consideration}

The research applied for ethical approval from Jawatankuasa Etika Penyelidikan (Manusia) of USM (JEPeM) under the JEPeM code: (USM/ JEPeM/17030189). Upon interviewing, the recording device was pointed out to the patients, informed consent was signed by each patient before starting the interview to approve using their data for research purposes and publications without revealing or indicating any information to their identity. To ensure privacy and anonymity, each patient was given a number (P01-P15). The interview transcripts were then prepared, reviewed, and sent to the participants for approval. Maintenance of high-level objectivity in discussion and analysis throughout the research has been assured.

\section{ACKNOWLEDGEMENT}

The authors thank the healthcare team at Hospital Universiti Sains Malaysia for their cooperation and thank Tasneem Taha, MD for her help in interviewing patients.

\section{CONFLICT OF INTEREST}

The authors declare no conflict of interest.

\section{REFERENCES}

1. Nouri Al, Hassali MA. Assessment of kidney stone disease prevalence in a teaching hospital. Afr J Urol. 2018;24(3):180-85. doi: 10.1016/j.afju.2018.05.003.

2. Türk C, Petrík A, Sarica K, Seitz C, Skolarikos A, Straub M, Knoll T. EAU guidelines on interventional treatment for urolithiasis. Eur Urol. 2016;69(3):475-82. doi: 10.1016/j.eururo.2015.07.041, PMID 26344917.

3. Skolarikos A. Medical treatment of urinary stones. Curr Opin Urol. 2018;28(5):403-07. doi: 10.1097/MOU.0000000000000523, PMID 29939860.

4. Nouri A, Azmi Hassali M, Amir Hamza A. The role of corticosteroids in the management of kidney stones disease: a systematic review. clinical-practice; 14(7). doi: 10.4172/clinical-practice.1000133.

5. Cabri J, Lambrechts S, Pollard M, Kwan L, Zhang H, Pena A, Brownstein D, Liu H, Chang J, Alden J, Patel N, Dunn M, Saigal C. Mp39-15 urolithiasis treatment preferences and the impact of a decision aid on treatment choice. J Urol. 2019;201(Supplement 4);Suppl 4:e550-e50. doi: 10.1097/01. JU.0000556060.91998.49.

6. Kuo RL, Aslan P, Abrahamse PH, Matchar DB, Preminger GM. Incorporation of patient preferences in the treatment of upper urinary tract calculi: A decision analytical view. J Urol. 1999;162(6):1913-8; discussion 1918. doi: 10.1016/ s0022-5347(05)68067-6, PMID 10569536.

7. Rabah DM, AlOmar M, Binsaleh S, Arafa MA. Health related quality of life in ureteral stone patients: post-ureterolithiasis. Urol Res. 2011;39(5):385-8. doi: 10.1007/s00240-011-0375-9, PMID 21461963

8. Ventegodt S, Merrick J, Anderson J. Quality of life as medicine: A pilot studyof patients with chronic illness and pain. Sci World J. 2003;3:520-32. doi: 10.1100/ tsw.2003.36.

9. Diniz DH, Blay SL, Schor N. Anxiety and depression symptoms in recurrent painful renal lithiasis colic. Braz J Med Biol Res. 2007:40(7):949-55. doi: 10.1590/s0100-879x2007000700009, PMID 17653448

10. Diniz DH, Schor N, Blay SL. Stressful life events and painful recurrent colic of renal lithiasis. J Urol. 2006;176(6 Pt 1):2483-7; discussion 2487. doi: 10.1016/j. juro.2006.07.156, PMID 17085135.

11. Morse M, Field A. Qualitative research methods for health professionals. SAGE; 1995.

12. Green J, Thorogood N. Qualitative methods for health research. SAGE; 2018.

13. Starks H, Trinidad SB. Choose your method: A comparison of phenomenology, discourse analysis, and grounded theory. Qual Health Res. 2007;17(10):1372-80. doi: 10.1177/1049732307307031, PMID 18000076.

14. Yardley L. Dilemmas in qualitative health research. Psychol Health 2000;15(2):215-28. doi: 10.1080/08870440008400302

15. Nouri Al, Abdi AM, Hassali MA. Synopsis of research methodologies: A brief guide for pharmacists. J Pharm Res Int. 2018;24(5):1-16. doi: 10.9734/ JPRI/2018/42207.

16. Creswell JW. Qualitative inquiry and research design: choosing among five approaches. Sage publications; 2012.

17. Wright PJ, English PJ, Hungin AP, Marsden SN. Managing acute renal colic across the primary-secondary care interface: A pathway of care based on evidence and consensus. BMJ. 2002:325(7377):1408-12. doi: 10.1136/ bmj.325.7377.1408, PMID 12480861.

18. Cheungpasitporn W, Thongprayoon $C$, O'corragain OA, Edmonds PJ, Ungprasert $P$ Kittanamongkolchai $W$, et al. The risk of kidney cancer in patients with kidney stones: A systematic review and meta-analysis. Q J Med. 2015;108(3):205-12. doi: 10.1093/qjmed/hcu195, PMID 25208892.

19. Diniz DH, Blay SL, Schor N. Quality of life of patients with nephrolithiasis and recurrent painful renal colic. Nephron Clin Pract. 2007;106(3):c91-7. doi: 10.1159/000102995, PMID 17522476.

20. Bensalah K, Tuncel A, Gupta A, Raman JD, Pearle MS, Lotan Y. Determinants of quality of life for patients with kidney stones. J Urol. 2008;179(6):2238-43 discussion 43. doi: 10.1016/j.juro.2008.01.116, PMID 18423704.

21. Dauw $C A$, Yi Y, Bierlein MJ, Yan P, Alruwaily AF, Ghani KR, Wolf JS, Hollenbeck BK, Hollingsworth JM. Medication nonadherence and effectiveness of preventive pharmacological therapy for kidney stones. J Urol. 2016;195(3):648-52. doi: 10.1016/j.juro.2015.10.082, PMID 26485048.

22. Fisang C, Anding R, Müller SC, Latz S, Laube N. Urolithiasis-an interdisciplinary diagnostic, therapeutic and secondary preventive challenge. Dtsch Arztebl Int. 2015;112(6):83-91. doi: 10.3238/arztebl.2015.0083, PMID 25721435.

23. Türk C, Petrík A, Sarica K, Seitz C, Skolarikos A, Straub M, Knoll T. Eau guidelines on diagnosis and conservative management of urolithiasis. Eur Urol. 2016;69(3):468-74. doi: 10.1016/j.eururo.2015.07.040, PMID 26318710.

24. Ziemba JB, Matlaga BR. Guideline of guidelines: Kidney stones. BJU Int. 2015;116(2):184-9. doi: 10.1111/bju.13080, PMID 25684222.

25. Chandrasekar T, Monga M, Nguyen M, Low RK. Internet-based patient survey on urolithiasis treatment and patient satisfaction. J Endourol. 2015;29(6):725-29. doi: 10.1089/end.2014.0643, PMID 25365030

26. Xu H, Zisman AL, Coe FL, Worcester EM. Kidney stones: an update on current pharmacological management and future directions. Expert Opin Pharmacother. 2013;14(4):435-47. doi: 10.1517/14656566.2013.775250, PMID 23438422.

27. Pope C, Ziebland S, Mays N. Qualitative research in health care. Analysing qualitative data. BMJ. 2000;320(7227):114-16. doi: 10.1136/bmj.320.7227.114 PMID 10625273.

28. Byrne MM. Understanding life experiences through a phenomenological approach to research. AORN J. 2001;73(4):830-2. doi: 10.1016/s00012092(06)61812-7, PMID 11303472

29. Kravitz R. Patient satisfaction with health care: Critical outcome or trivial pursuit? J Gen Intern Med. 1998;13(4):280-82. doi: 10.1046/j.1525-1497.1998.00084.X, PMID 9565395 


\section{Appendix: Interview Guide}

\section{Satisfaction about Urolithiasis Pain Management}

- What made you go to the doctor?

- How long have you stayed in pain before seeking medical care?

- What did you take before you approach the doctor? How helpful was it?

- As you know, what is the status of your kidney stone?

- Do you know what has been prescribed by your physician to manage your kidney stones?

- Is your pain adequately managed? How do you think could it be improved?

- After seeking medical advice, what do you do to manage your pain other than taking the prescribed drugs?

- How the pain impacts your typical day?

- Did a painful episode force you to go to the emergency department?

- Do you feel any side effects from the drugs you are currently taking for your pain?

- What is it and how did you manage it?

- To what extent you think your condition affected your quality of life?

- Have you felt that you lost interest in likable activities, and you do not want to engage in any entertainment because of pain?

- How would you rate your pain currently at our interview, now?

- Do you feel you need to take a painkiller now?

\section{Satisfaction towards treatment strategy}

- What treatment you had to manage kidney stones? Describe it?
- Why did you choose that option for treatment?

- How satisfied are you with that option?

- If you had to choose again, would you choose it?

- Are you afraid of having surgery or any other invasive procedures?

- Do you believe it was the best option for you?

Perception towards kidney stones disease management

- Did your physician provide you with adequate information about the prevention of kidney stones?

- Do you think the given information will help you to change your diet and lifestyle?

- What did you do to change your lifestyle to manage and prevent kidney stones?

- What did your doctor prescribe to prevent the development of kidney stones in the future?

- Do you take your medications as directed by your doctor?

- How confident are you that prescribed drugs are helpful to manage your condition?

- How does your family react to your pain?

- Do you suffer from other co-morbidities? How do you think it is related to your kidney stones?

- Do you feel that the pain is not going to end, and you will be like this for life long? Why?

- Have you ever tried traditional medicine because you do not believe in taking pills? 